\title{
Correlation Between Changes in Lamina Cribrosa Structure and Visual Field in Primary Open-Angle Glaucoma
}

\section{Ahmed El Basty \\ Raouf Gaber (D) \\ Ahmed Elmaria (ID \\ Moataz Sabry (D) \\ Tarek R Hussein}

Department of Ophthalmology, Tanta University, Tanta, Gharbeya Province, Egypt
Correspondence: Raouf Gaber

Tanta University Eye Hospital, The Faculty of Medicine, El-Gash St. Medical Campus, Tanta, Gharbeya Province, 31527, Egypt Tel +20l557673775

Email Raouf.a.gaber@gmail.com
Purpose: To investigate the correlation between changes in lamina cribrosa (LC) structure using enhanced depth imaging (EDI) and severity of visual field (VF) affection in primary open-angle glaucoma (POAG).

Patients and Methods: This prospective cross-sectional study was carried out on 52 glaucomatous eyes of 28 POAG patients who attended Tanta University Eye Hospital and 40 normal eyes of 20 age-matched normal subjects from April 2020 to March 2021. POAG patients were classified according to the modified Hodapp-Anderson-Parrish grading scale based on the MD of the standard automated perimetry (SAP) visual field into two groups: group (1) - mild-tomoderate POAG patients (MD $\leq 12 \mathrm{~dB}$ ), group (2) - severe POAG patients (MD $\geq 12 \mathrm{~dB}$ ) and the third group included normal (control) age- and gender-matched individuals.

Results: There was no statistically significant difference between the three groups regarding lamina cribrosa thickness nor lamina cribrosa area and there was no statistically significant correlation between MD and LC thickness, LC area (P-value $=0.395$ and 0.644). There was a statistically significant correlation between $\mathrm{MD}$ and anterior lamina cribrosa surface depth $(\mathrm{P}$-value $=0.002)$ and there was a statistically significant positive correlation between MD and prelaminar neural tissue (PLNT) thickness and prelaminar neural tissue (PLNT) area (P-value $=0.023$ and $<0.001$, respectively).

Conclusion: EDI-OCT is a useful biomarker of structural changes in $\mathrm{ONH}$ and LC, and we recommended it to be a part of the routine monitoring of patients with POAG.

Keywords: EDI, blindness, biomarker, lamina cribrosa, PLNT thickness

\section{Introduction}

Glaucoma is identified as a potentially progressive characteristic optic neuropathy, which includes structural or morphological alterations in the head of the optic nerves $(\mathrm{ONH})$, associated with excavation of $\mathrm{ONH}$ and lamina cribrosa (LC) deformation and development of characteristic patterns of functional worsening of the visual field (VF) due to neurodegeneration of the retinal ganglion cell (RGCs) axons. $^{1-3}$

Glaucoma is the second most frequent blindness condition globally after cataract. In 2020, about 79 million people suffer from glaucoma around the world.,5 The number of individuals affected by glaucoma continues to rise, and it is estimated that it may reach up to 111.8 million in 2040 , worldwide. ${ }^{6}$

Primary open-angle glaucoma (POAG) is the most prevalent type of glaucoma worldwide (about $70 \%$ of the cases of glaucoma). ${ }^{3}$ 
The laminar area of ONH is the major place of insult to RGCs axonal damage in both human and experimental animals with glaucoma. ${ }^{7}$ In glaucoma, the LC structure is significantly affected by the remodeling of its connective tissue by multiple mechanisms. This could change the physiology of resident cells and LC capillaries, which probably contribute to glaucomatous damage. ${ }^{8,9}$

Advances in the field of OCT including enhanced depth imaging-optical coherence tomography (EDI-OCT) provide the means to evaluate structural modifications of the $\mathrm{ONH}$ and $\mathrm{LC}^{10}$

Functional diagnosis is mostly based on visual field analysis by standard automated perimetry (SAP). SAP is the reference test and the most widely used approach for evaluation of functional deterioration of glaucoma, ${ }^{11}$ documentation and tracking of functional regression in glaucoma. ${ }^{12}$

There are limited data on the correlation between the structural changes in optic nerve head and the functional assessment of glaucoma using visual field analysis. In our study, we evaluate the correlation between the structure of ONH using OCT EDI and functional changes in POAG patients using visual field analysis. Most of the studies done before focused mainly on Lamina cribrosa thickness and anterior lamina cribrosa surface depth (depth of the cup). In our manuscript, we tried to increase our understanding of changes in lamina cribrosa (LC) by measuring LC area and thickness and structures related to $\mathrm{LC}$ as prelaminar neural tissue (PLNT) by measuring PLNT thickness and area.

\section{Patients and Methods}

This prospective cross-sectional study was carried out on 52 glaucomatous eyes of 28 POAG patients who attended Tanta University Eye Hospital and 40 normal eyes of 20 agematched normal subjects from April 2020 to March 2021.

There is no risk to the participants of the study at all and ethical committee approval number 33751/3/20 from Tanta University was obtained. The study was conducted in accordance with the tenets of the Declaration of Helsinki and the guidelines of good clinical practice. Full counseling of the participants in this research about the nature of the study was obtained and informed consent was taken.

Inclusion criteria:

1. Patients diagnosed with primary open-angle glaucoma.

2. Patients older than 40 years of age.

3. Both genders were included in the study.
4. Patients has spherical correction between $(-6 \mathrm{D}$ and $+3 \mathrm{D})$ and cylindrical correction within $\pm 3 \mathrm{D}$.

Exclusion criteria:

1. Patients with any associated systemic (eg, neurologic disease) or ocular diseases other than glaucoma that affect ONH or VF testing.

2. Patients who had any previous ocular surgery or trauma.

3. Eyes with unreliable VF (defined as follows: falsenegative $>25 \%$, false-positive $>25 \%$ and fixation loss $>20 \%$ ).

4. Patients with poor quality OCT images (eg, dense cataract or vitreous hemorrhage).

5. Patients with congenital anomalies of the optic nerve (eg, optic nerve hypoplasia, morning glory disc anomaly, optic disc coloboma and optic nerve pit).

POAG patients were grouped according to the modified Hodapp-Anderson- Parrish grading scale based on the MD of the standard automated perimetry (SAP) visual field $^{13}$ into two groups: group (1) mild-to-moderate POAG patients (MD $\leq 12 \mathrm{~dB}$ ), group (2) severe POAG patients $(\mathrm{MD} \geq 12 \mathrm{~dB}$ ) and the third group included normal (control) age- and gender-matched individuals.

Detailed medical and surgical history was obtained from all the participants followed by a complete ophthalmological examination, in particular:

A. Measurement of uncorrected and best-corrected distance visual acuity (UCVA, BCVA) using a Snellen chart in decimal notation.

B. Anterior segment fully examined using slit-lamp and gonioscopic examination for the AC angle using Goldmann 3-mirror lens with the slit lamp for any abnormality to exclude angle-closure and secondary glaucomas.

C. All participants underwent a Posterior segment examination using slit-lamp fundus biomicroscopy using $\mathrm{a}+78.00$ D lens.

\section{Visual Field Testing}

VF examination by Humphrey field analyzer (Carl-Zeiss Meditec, Dublin, CA; SITA standard strategy, program 24-2). All participants underwent VF testing to determine MD and PSD using the standard automated perimetry Full Threshold Standard 24-2 strategy size III white stimulus at the same time with imaging. VF loss was expressed as MD from normal. We used the VF mean deviation (MD) for analysis of VF affection. 


\section{Optical Coherence Tomography} (Spectralis; Heidelberg Engineering Co., Heidelberg, Germany) of the RNFL Thickness

Peripapillary RNFL thickness assessment using the $3.4 \mathrm{~mm}$ circular scan centered on the optic disc, the peripapillary RNFL was measured in the four quadrants and the average RNFL thickness was taken as the main parameter.

\section{EDI-OCT Imaging (Spectralis; Heidelberg Engineering Co., Heidelberg, Germany) for $\mathrm{LC}$ and $\mathrm{ONH}$}

Parameters of LC and ONH were measured manually by experienced examiners masked to patient's clinical data:

a) The thickness of the LC is defined as the distance between the anterior and posterior borders of the highly reflective region of the $\mathrm{ONH}$ in the EDI-OCT B-scans. b) The area of the LC is defined as the area between the anterior and posterior borders of the highly reflective region. c) Prelaminar neural tissue (PLNT) is defined as the perpendicular distance between the anterior PLNT surface and the anterior surface of the LC. d) PLNT area is defined as the area between the anterior PLNT surface and the anterior surface of the LC. e) The anterior lamina cribrosa surface depth (ALCSD) is defined as the distance from the line connecting the two Bruch's membrane opening (BMO) edges (reference line) to the anterior LC surface (Figures 1 and 2).

\section{Statistical Analysis}

All data analysis was performed using (SPSS V20) statistical software. Qualitative data were described using
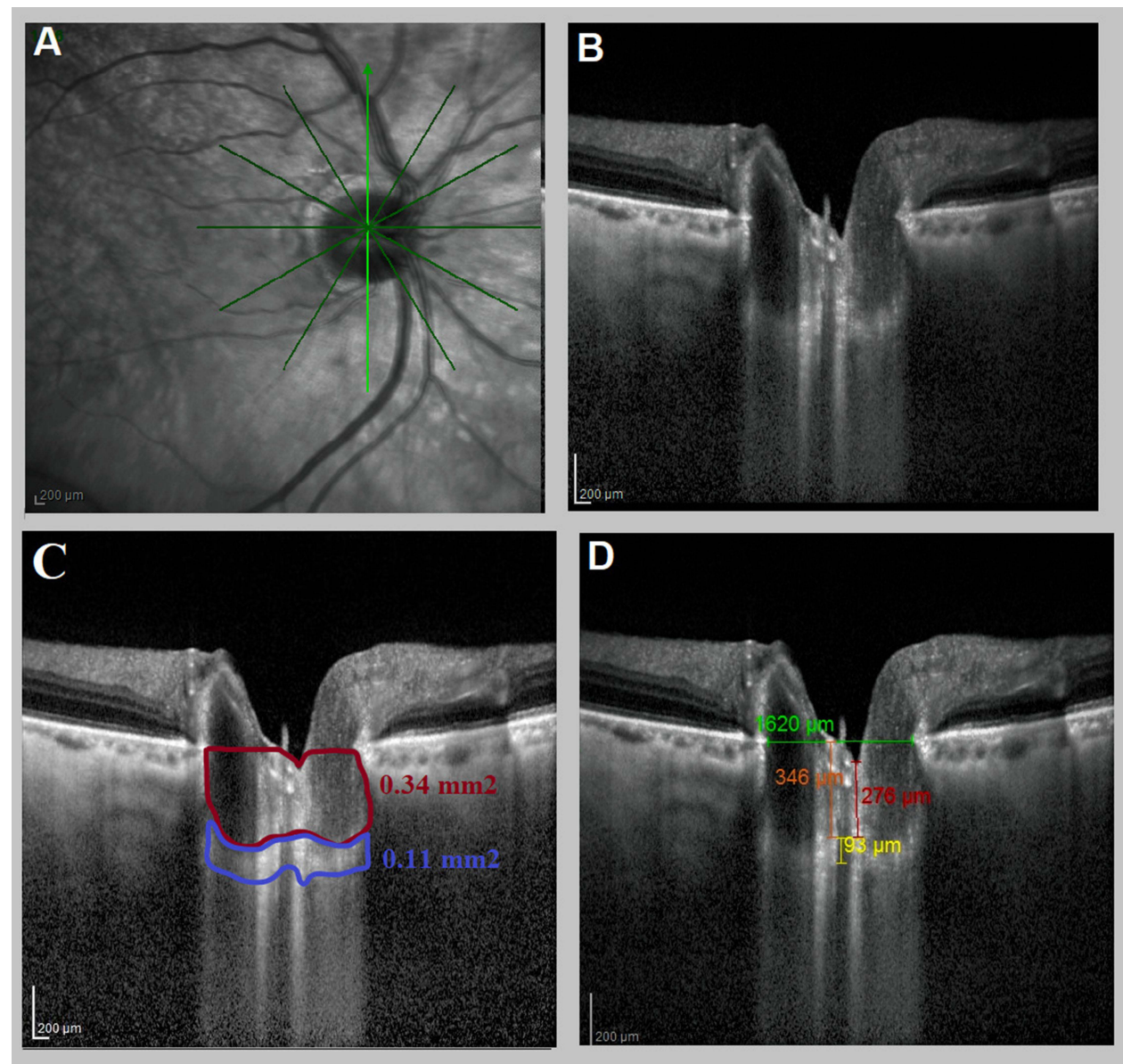

Figure I Right eye of a mild POAG patient (MD = -4.35). (A) The axial scans of the optic nerve head. (B) The enhanced depth imaging with spectral-domain optical coherence tomography (EDI-OCT) device (Spectralis, Heidelberg Engineering, Heidelberg, Germany) of lamina cribrosa (LC). (C) EDI-OCT assessment of LC showed that: Blue square showing the lamina cribrosa area $\left(0.1 \mathrm{I} \mathrm{m^{2 }}\right)$ and the red square prelaminar neural tissue area $\left(0.34 \mathrm{~mm}^{2}\right)$. (D) EDI-OCT assessment of LC showed that: yellow line showing LC thickness $93 \mu \mathrm{m}$, red line showing prelaminar neural tissue thickness $(276 \mu \mathrm{m})$, and orange line showing anterior lamina cribrosa surface depth ( $346 \mu \mathrm{m})$. Green line showing reference line connecting both ends of Bruch's membrane opening. 

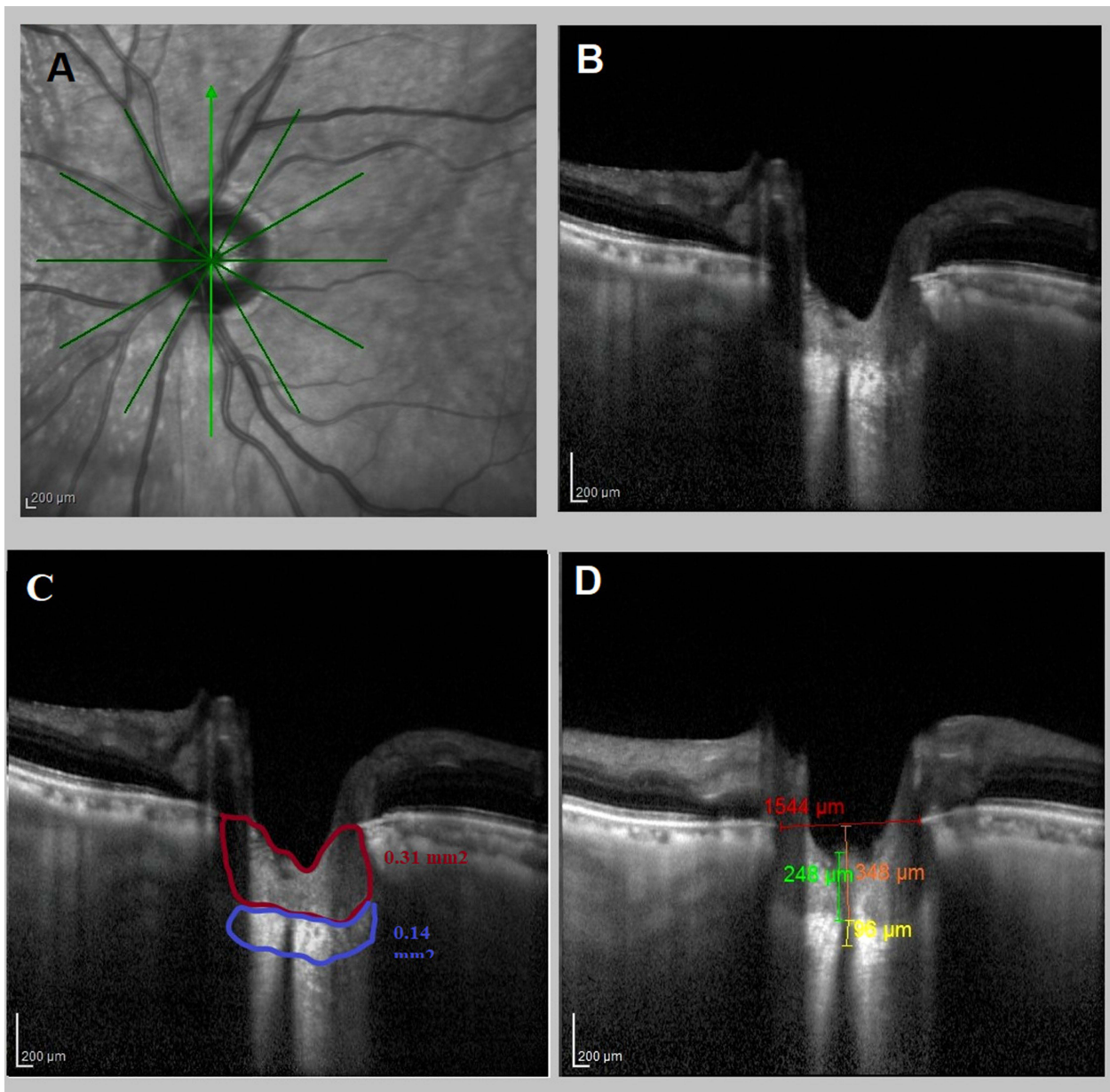

Figure 2 Left eye of a mild POAG patient $(M D=-5.5 I)$. (A) The axial scans of the optic nerve head. (B) The enhanced depth imaging with spectral-domain optical coherence tomography (EDI-OCT) device (Spectralis, Heidelberg Engineering, Heidelberg, Germany) of lamina cribrosa. (C) EDI-OCT assessment of LC showed that: Blue square showing the lamina cribrosa area $\left(0.14 \mathrm{~mm}^{2}\right)$ and the red square prelaminar neural tissue area $\left(0.3 \mathrm{I} \mathrm{mm}^{2}\right)$. (D) EDI-OCT assessment of LC showed that: yellow line showing LC thickness $96 \mu \mathrm{m}$, green line showing prelaminar neural tissue thickness $(248 \mu \mathrm{m})$, and orange line showing anterior lamina cribrosa surface depth $(348 \mu \mathrm{m})$. Red line showing reference line connecting both ends of Bruch's membrane opening.

frequency and percent. Quantitative data were described using mean, median, standard deviation and range (minimum and maximum). The significance level was set at P-value $<0.05$.

\section{Results}

The baseline demographics and clinical characteristics of the patients are summarized in Tables 1 and 2, respectively.

The mean best corrected visual acuity (BCVA) was 0.068 \pm 0.119 LogMAR in mild-to-moderate glaucoma group, $1.113 \pm 0.589 \operatorname{LogMAR}$ in the severe glaucoma group and $0.0 \pm 0.0$ LogMAR in the control group (3). BCVA was significantly lower in the severe glaucoma group than mildto-moderate glaucoma group and control group, but there was no statistically significant difference between mild-to- moderate and control group. LC thickness and area were not statistically significantly different between all groups ( $\mathrm{p}$-value $=0.838$ and 0.716 , respectively).

The mean PLNT thickness was $158.900 \pm 73.689 \mu \mathrm{m}$ in the mild-to-moderate group, $121.455 \pm 70.050 \mu \mathrm{m}$ in the severe glaucoma group and $217.750 \pm 142.378 \mu \mathrm{m}$ in the control group. PLNT thickness was statistically significant thinner in the severe glaucoma group in comparison to the control group ( $\mathrm{p}$-value $=0.003$ ) but not statistically significant between the mild-tomoderate group and control group ( $\mathrm{p}$-value $=0.440)$ and between the mild-to-moderate group and severe glaucoma group (p-value $=0.070)$. The mean PLNT area was $(0.385 \pm$ $\left.0.099 \mathrm{~mm}^{2}\right)$ in the mild-to-moderate glaucoma group, $\left(0.282 \pm 0.114 \mathrm{~mm}^{2}\right)$ in the severe glaucoma group and $\left(0.488 \pm 0.109 \mathrm{~mm}^{2}\right)$ in the control group. PLNT area was 
Table I Demographic Characteristics (the Age and Gender Distribution) of the Study Groups

\begin{tabular}{|c|c|c|c|c|c|c|c|c|c|}
\hline & & \multicolumn{6}{|c|}{ Groups } & \multicolumn{2}{|c|}{ ANOVA } \\
\hline & & \multicolumn{2}{|c|}{ Normal } & \multicolumn{2}{|c|}{ Mild to Moderate } & \multicolumn{2}{|c|}{ Severe } & $\boldsymbol{F}$ & P-value \\
\hline \multirow[t]{2}{*}{ Age (Years) } & Range & \multicolumn{2}{|c|}{$43-69$} & \multicolumn{2}{|c|}{$43-70$} & \multicolumn{2}{|c|}{$45-72$} & \multirow[t]{2}{*}{1.115} & \multirow[t]{2}{*}{0.337} \\
\hline & Mean \pm SD & \multicolumn{2}{|c|}{$52.450 \pm 7.891$} & \multicolumn{2}{|c|}{$54.500 \pm 7.711$} & \multicolumn{2}{|c|}{$56.833 \pm 8.892$} & & \\
\hline \multicolumn{2}{|l|}{ Chi-Square } & $\mathrm{N}$ & $\%$ & $\mathrm{~N}$ & $\%$ & $\mathrm{~N}$ & $\%$ & $x^{2}$ & P-value \\
\hline \multirow[t]{2}{*}{ Sex } & Male & 6 & 30.00 & 6 & 37.50 & 9 & 75.00 & \multirow[t]{2}{*}{6.552} & \multirow[t]{2}{*}{0.038} \\
\hline & Female & 14 & 70.00 & 10 & 62.50 & 3 & 25.00 & & \\
\hline
\end{tabular}

Abbreviation: SD, standard deviation.

Table 2 Clinical Characteristics of the Study Groups

\begin{tabular}{|c|c|c|c|c|c|c|c|c|c|}
\hline & & \multicolumn{3}{|c|}{ Groups } & \multicolumn{2}{|c|}{ ANOVA } & \multicolumn{3}{|c|}{ Tukey's Test } \\
\hline & & $\begin{array}{l}\text { Control } \\
\text { Group }\end{array}$ & $\begin{array}{c}\text { Mild-to-Moderate POAG } \\
\text { Group }\end{array}$ & $\begin{array}{l}\text { Severe POAG } \\
\text { Group }\end{array}$ & $\boldsymbol{F}$ & P-value & $N \& M$ & N\&S & M\&S \\
\hline \multirow[t]{2}{*}{ BCVA Log MAR } & Range & $0.0-0.0$ & $0.0-0.48$ & $0.18-1.77$ & \multirow[t]{2}{*}{114.334} & \multirow[t]{2}{*}{$<0.001 *$} & \multirow[t]{2}{*}{0.605} & \multirow[t]{2}{*}{$<0.001 *$} & \multirow[t]{2}{*}{$<0.001 *$} \\
\hline & Mean $\pm S D$ & $0.0 \pm 0.0$ & $0.068 \pm 0.119$ & $1.113 \pm 0.589$ & & & & & \\
\hline \multirow{2}{*}{$\begin{array}{l}\text { Spherical Equivalent } \\
\text { (D) }\end{array}$} & Range & $-3 \pm 2.75$ & $-2 \pm 2.5$ & $-4.75 \pm 1$ & \multirow[t]{2}{*}{11.783} & \multirow[t]{2}{*}{$<0.001 *$} & \multirow[t]{2}{*}{0.976} & \multirow[t]{2}{*}{$<0.001 *$} & \multirow[t]{2}{*}{$<0.001^{*}$} \\
\hline & Mean $\pm S D$ & $-0.39 \pm 1.02$ & $-0.3 \pm 1.242$ & $-1.818 \pm 1.536$ & & & & & \\
\hline \multirow[t]{2}{*}{ IOP (mm/Hg) } & Range & $10-16$ & $10-24$ & $10-26$ & \multirow[t]{2}{*}{12.194} & \multirow[t]{2}{*}{$<0.00 I^{*}$} & \multirow[t]{2}{*}{$<0.001 *$} & \multirow[t]{2}{*}{0.096} & \multirow[t]{2}{*}{0.067} \\
\hline & Mean \pm SD & $13.5 \pm 1.4$ & $17 \pm 3.487$ & $|5 \pm 4.26|$ & & & & & \\
\hline \multirow[t]{2}{*}{$C / D$ ratio } & Range & $0.1-0.5$ & $0.2-0.6$ & $0.5-0.9$ & \multirow[t]{2}{*}{107.408} & \multirow[t]{2}{*}{$<0.001 *$} & \multirow[t]{2}{*}{$<0.001 *$} & \multirow[t]{2}{*}{$<0.001 *$} & \multirow[t]{2}{*}{$<0.001 *$} \\
\hline & Mean \pm SD & $0.275 \pm 0.12$ & $0.440 \pm 0.122$ & $0.745 \pm 0.126$ & & & & & \\
\hline
\end{tabular}

Note: *Significance at $p<0.05$.

Abbreviations: C/D, cup disc; IOP, intraocular pressure; $M$, mild-to-moderate POAG group; N, control group; POAG, primary open-angle glaucoma; SD, standard deviation; $\mathrm{S}$, severe POAG group.

statistically significantly smaller in the severe glaucoma group in comparison to the mild-to-moderate group and normal control group and also between the mild-tomoderate group and control group (Table 3).

The mean ALCSD was $413.200 \pm 119.014 \mu \mathrm{m}$ in the mildto-moderate group, $510.909 \pm 164.0962 \mu \mathrm{m}$ in the severe glaucoma group and $397.125 \pm 117.720 \mu \mathrm{m}$ in the control group. ALCSD was showing a statistically significant increase in the severe glaucoma group in comparison to both the mildto-moderate group and control group ( $\mathrm{p}$-value $=0.004$ and $\mathrm{p}$-value $=0.025)$ but the difference was not statistically significant between the mild-to-moderate glaucoma group and the control group ( $\mathrm{p}$-value $=0.867$ ).

There was a statistically significant positive correlation between MD and PLNT thickness and PLNT area (P-value $=0.023$ and $<0.001$, respectively) and a statistically significant negative correlation between MD and anterior lamina cribrosa surface depth $(\mathrm{P}$-value $=0.002)$. Also, there was no statistically significant correlation between $\mathrm{MD}$ and LC thickness, LC area (P-value $=0.395$ and 0.644) (Table 4).

\section{Discussion}

Glaucoma is a worldwide leading cause of an irreversible decrease in quality of life and vision loss. ${ }^{1}$ Glaucomatous damage is typically characterized by structural changes such as distinct cupping of the ONH and thinning of the RNFL associated with functional loss (patterns of VF defects). ${ }^{14,15}$

EDI-OCT is a new approach in OCT that has been shown to reliably capture images of the retina and choroid in various ocular diseases ${ }^{16}$ and can capture images of deep structures within ONH such as LC and PLNT. ${ }^{17,18}$ This approach shows promising progress that can help for diagnosis and follow-up for the structural changes that occur in glaucomatous patients. ${ }^{17,18}$ 
Table 3 Optic Nerve Head Parameters in Different Glaucoma Groups

\begin{tabular}{|c|c|c|c|c|c|c|c|c|c|}
\hline & & \multicolumn{3}{|c|}{ Groups } & \multicolumn{2}{|c|}{ ANOVA } & \multicolumn{3}{|c|}{ Tukey's Test } \\
\hline & & Normal & Mild to Moderate & Severe & $\boldsymbol{F}$ & P-value & $N \& M$ & N\&S & M\&S \\
\hline \multirow{2}{*}{$\begin{array}{l}\text { LC } \\
\text { thickness }(\mathrm{mm})\end{array}$} & Range & $93-213$ & $88-221$ & $98-306$ & \multirow[t]{2}{*}{0.177} & \multirow[t]{2}{*}{0.838} & & & \\
\hline & Mean $\pm S D$ & $149.525 \pm 34.032$ & $147.267 \pm 37.378$ & $143.636 \pm 42.812$ & & & & & \\
\hline \multirow{2}{*}{$\begin{array}{l}\text { LC } \\
\text { area }\left(\mathrm{mm}^{2}\right)\end{array}$} & Range & $0.14-0.36$ & $0.11-0.41$ & $0.1-0.57$ & \multirow[t]{2}{*}{0.335} & \multirow[t]{2}{*}{0.716} & & & \\
\hline & Mean $\pm S D$ & $0.220 \pm 0.045$ & $0.210 \pm 0.067$ & $0.206 \pm 0.095$ & & & & & \\
\hline \multirow{2}{*}{$\begin{array}{l}\text { PLNT } \\
\text { thickness (mm) }\end{array}$} & Range & $29-483$ & $53-295$ & $35-256$ & \multirow[t]{2}{*}{6.093} & \multirow[t]{2}{*}{$0.003^{*}$} & \multirow[t]{2}{*}{0.070} & \multirow[t]{2}{*}{$0.003^{*}$} & \multirow[t]{2}{*}{0.440} \\
\hline & Mean $\pm S D$ & $217.750 \pm 142.378$ & $158.900 \pm 73.689$ & $|2| .455 \pm 70.050$ & & & & & \\
\hline \multirow{2}{*}{$\begin{array}{l}\text { PLNT } \\
\text { area }\left(\mathrm{mm}^{2}\right)\end{array}$} & Range & $0.13-0.69$ & $0.18-0.56$ & $0.14-0.48$ & \multirow[t]{2}{*}{16.961} & \multirow[t]{2}{*}{$<0.001 *$} & \multirow[t]{2}{*}{$0.047^{*}$} & \multirow[t]{2}{*}{$<0.00$ I $^{*}$} & \multirow[t]{2}{*}{$0.003^{*}$} \\
\hline & Mean $\pm S D$ & $0.448 \pm 0.109$ & $0.385 \pm 0.099$ & $0.282 \pm 0.114$ & & & & & \\
\hline \multirow[t]{2}{*}{ ALCSD (mm) } & Range & $125-634$ & $198-644$ & $209-851$ & \multirow[t]{2}{*}{5.719} & \multirow[t]{2}{*}{$0.005^{*}$} & \multirow[t]{2}{*}{0.867} & \multirow[t]{2}{*}{$0.004^{*}$} & \multirow[t]{2}{*}{0.025} \\
\hline & Mean $\pm S D$ & $397.125 \pm 117.720$ & $413.200 \pm 119.014$ & $510.909 \pm 164.962$ & & & & & \\
\hline
\end{tabular}

Note: *Significance at $\mathrm{p}<0.05$.

Abbreviations: ALCSD, anterior lamina cribrosa surface depth; LC, lamina cribrosa; PLNT, prelaminar neural tissue.

Table 4 Correlation Between Mean Deviation of Visual Field and Optic Nerve Head Parameters

\begin{tabular}{|l|c|c|}
\hline \multicolumn{3}{|c|}{ Correlations } \\
\hline & \multicolumn{2}{|c|}{ MD (DP) } \\
\cline { 2 - 3 } & $r$ & P-value \\
\hline LC thickness (mm) & 0.120 & 0.395 \\
LC area $\left(\mathrm{mm}^{2}\right)$ & 0.066 & 0.644 \\
PLNT thickness (mm) & 0.314 & $0.023^{*}$ \\
PLNT area $\left(\mathrm{mm}^{2}\right)$ & 0.492 & $<0.001^{*}$ \\
ALCSD $(\mathrm{mm})$ & -0.416 & $0.002^{*}$ \\
\hline
\end{tabular}

Note: *Significance at $\mathrm{p}<0.05$.

Abbreviations: ALCSD, anterior lamina cribrosa surface depth; MD, mean deviation; PLNT, prelaminar neural tissue.

In the present study, we used EDI-OCT imaging for the assessment of structural changes of $\mathrm{ONH}$ in $\mathrm{POAG}$ patients. The parameters of interest were LC thickness, LC area, PLNT thickness, PLNT area and the ALCSD. These parameters were analyzed and correlated with mean deviation of the visual field, which considered the parameter of functional deterioration in POAG patients.

In the current study, LC thickness and area were not statistically significantly different between all groups. This agreed with Lopes et $\mathrm{al}^{18}$ who conducted a study on a total of 73 eyes from 73 participants (39 patients with glaucoma and 34 controls). He found insignificant differences in LC thickness or area when compared between the enrolled healthy participants and glaucomatous patients with a broad range of disease stages.
Contrary to these results, Fayed ${ }^{19}$ concludes that there is a generalized decrease in LC thickness in the glaucomatous patients compared with healthy controls and the LC morphology can help differentiate normal eyes from glaucomatous eyes. The mean values of the LC thickness in the POAG group were $188.4 \pm 15.8 \mu \mathrm{m}$ and the mean values of the LC thickness in the normal control group were $395.6 \pm 20.6 \mu \mathrm{m}$. This may be explained by the absence of IOP lowering medication effect on lamina cribrosa biomechanics in his study.

Contrary to our study, Kim et $\mathrm{al}^{20}$ and Park et $\mathrm{al}^{17}$ found that LC thickness decreased with the progression of the disease severity.

In the present study, prelaminar neural tissue thickness was statistically thinner in the severe glaucoma group than in the control group. This coincides with Lopes et $\mathrm{al}^{18}$ who showed that the PLNT parameters significantly decreased in glaucomatous eyes than control eyes.

The current study shows a statistically significant positive correlation between MD and PLNT area and a negative correlation between MD and ALCSD. No statistically significant correlation between $\mathrm{MD}$ and $\mathrm{LC}$ thickness, LC area, PLNT thickness.

In agreement with the results in the present study, Lopes et $\mathrm{al}^{18}$ found no significant correlations were found for LC thickness or area when compared with both VF MD in enrolled healthy participants and glaucomatous patients with various stages of disease stages. Also, Daguman and Delfin ${ }^{21}$ study detected no strong correlation 
between LC thickness to the severity of VF test results (LC thickness $r=0.160, \mathrm{p}=0.274$ ).

Contrary to the results of the present study, Kim et $\mathrm{al}^{20}$ found a significant correlation with LC thickness, with greater severity and VF deterioration associated with decreasing LC thickness. Also, Fayed ${ }^{19}$ study results were against these results as he found that there was a significant positive correlation between LC thickness and VF MD in glaucomatous patients.

On the contrary of the current study, the study carried out by Park et $\mathrm{al}^{17}$ concluded that the LC thickness showed a significant positive correlation with VF MD. In early POAG patients, LC thickness was $277.30 \pm 49.82$ $\mu \mathrm{m}$; in moderate POAG patients, the LC thickness was $205.26 \pm 20.73 \mu \mathrm{m}$; and in severe POAG patients, LC thickness was $165.44 \pm 9.32 \mu \mathrm{m}$. In early NTG patients, LC thickness was $192.44 \pm 19.87 \mu \mathrm{m}$; in moderate NTG patients LC thickness was $154.16 \pm 11.05 \mu \mathrm{m}$; and in severe NTG patients, LC thickness was $147.22 \pm 8.33 \mu \mathrm{m}$.

In agreement with the results in the present study, Lopes et $\mathrm{al}^{18}$ found significant structure-function positive correlations were found between VFI values and PLNT area $(\mathrm{R} 2=0.20)$.

This agreed with Fayed $^{19}$ found that there was a significant negative correlation between ALCSD and VF MD. Also, Kim et $\mathrm{al}^{20}$ found a significant negative correlation with ALCSD with greater severity associated with increasing ALCSD.

\section{Conclusion}

EDI-OCT is a valuable tool for evaluation of structural changes in LC and ONH and it has been suggested that it be used in the routine monitoring of patients with POAG.

\section{Disclosure}

The authors report no conflicts of interest in this work.

\section{References}

1. Casson RJ, Chidlow G, Wood JPM, Crowston JG, Goldberg I. Definition of glaucoma: clinical and experimental concepts. Clin Experiment Ophthalmol. 2012;40(4):341-349. doi:10.1111/j.14429071.2012.02773.x

2. Malik R, Swanson WH, Garway-Heath DF. The 'structure-function' relationship in glaucoma - past thinking and current concepts. Clin Experiment Ophthalmol. 2013;40(4):369-380.

3. Grzybowski A, Och M, Kanclerz P, Le C, De Moraes CG. Primary open angle glaucoma and vascular risk factors: a review of population based studies from 1990 to 2019. J Clin Med. 2020;9(3):761. doi: $10.3390 / \mathrm{jcm} 9030761$
4. Chen Z, Zheng X, Shen H, Zeng Z, Liu Q, Li Z. Combination of enhanced depth imaging optical coherence tomography and fundus images for glaucoma screening. J Med Syst. 2019;43(6). doi:10.1007/ s10916-019-1303-8

5. Rozpędek-Kamińska W, Wojtczak R, Szaflik JP, Szaflik J, Majsterek I. The genetic and endoplasmic reticulum-mediated molecular mechanisms of primary open-angle glaucoma. Int $J \mathrm{Mol}$ Sci. 2020;21(11):4171. doi:10.3390/ijms21114171

6. Tham Y-C, Li X, Wong TY, Quigley HA, Aung T, Cheng C-Y. Global prevalence of glaucoma and projections of glaucoma burden through 2040: a systematic review and meta-analysis. Ophthalmology. 2014;121(11):2081-2090. doi:10.1016/j.ophtha.2014.05.013

7. Downs JC, Girkin CA. Lamina cribrosa in glaucoma. Curr Opin Ophthalmol. 2017;28(2):113-119. doi:10.1097/ICU.0000000000000354

8. Ling YTT, Shi R, Midgett DE, Jefferys JL, Quigley HA, Nguyen TD. Characterizing the collagen network structure and pressure-induced strains of the human lamina cribrosa. Investig Ophthalmol Vis Sci. 2019;60(7):2406-2422. doi:10.1167/iovs.18-25863

9. Yu J, Gu R, Zong Y, et al. Relationship between retinal perfusion and retinal thickness in healthy subjects: an optical coherence tomography angiography study. Invest Ophthalmol Vis Sci. 2016;57(9): OCT204-10. doi:10.1167/iovs.15-18630

10. Abe RY, Gracitelli CPB, Diniz-Filho A, Tatham AJ, Medeiros FA. Lamina cribrosa in glaucoma: diagnosis and monitoring. Curr Ophthalmol Rep. 2015;3(2):74-84. doi:10.1007/s40135-015-0067-7

11. Gracitelli CPB, Zangwill LM, Diniz-filho A, et al. Detection of glaucoma progression in individuals of African descent compared with those of European Descent. JAMA Ophthalmol. 2018;136 (4):329-335. doi:10.1001/jamaophthalmol.2017.6836

12. Weinreb RN, Leung CKS, Crowston JG, et al. Primary open-angle glaucoma. Nat Rev Dis Primers. 2016;2:16067. doi:10.1038/ nrdp. 2016.67

13. Budenz DL, Rhee P, Feuer WJ, McSoley J, Johnson CA, Anderson DR. Comparison of glaucomatous visual field defects using standard full threshold and Swedish interactive threshold algorithms. Arch Ophthalmol (Chicago, Ill 1960). 2002;120 (9):1136-1141. doi:10.1001/archopht.120.9.1136

14. Weinreb RN, Aung T, Medeiros FA. The pathophysiology and treatment of glaucoma: a review. JAMA. 2014;311(18):1901-1911. doi:10.1001/jama.2014.3192

15. Tun TA, Atalay E, Baskaran M, et al. Association of functional loss with the biomechanical response of the optic nerve head to acute transient intraocular pressure elevations. JAMA Ophthalmol. 2018;136(2):184-192. doi:10.1001/jamaophthalmol.2017.6111

16. Dell'omo R, Costagliola C, Salvatore F, Cifariello F, Dell'Omo E. Enhanced depth imaging spectral-domain optical coherence tomography. Retina. 2010;30:378-379. doi:10.1097/IAE.0b013e3181c771eb

17. Park HYL, Jeon SH, Park CK. Enhanced depth imaging detects lamina cribrosa thickness differences in normal tension glaucoma and primary open-angle glaucoma. Ophthalmology. 2012;119 (1):10-20. doi:10.1016/j.ophtha.2011.07.033

18. Lopes FS, Matsubara I, Almeida I, et al. Structure-function relationships in glaucoma using enhanced depth imaging optical coherence tomography-derived parameters: a cross-sectional observational study. BMC Ophthalmol. 2019;19(1):4-11. doi:10.1186/s12886-019-1054-9

19. Fayed AA-H. Evaluation of the lamina cribrosa morphology in correlation to retinal nerve fiber layer thickness. Delta J Ophthalmol. 2017;18(3):166. doi:10.4103/DJO.DJO_21_17

20. Kim M, Bojikian KD, Slabaugh MA, Ding L, Chen PP. Lamina depth and thickness correlate with glaucoma severity. Indian J Ophthalmol. 2016;64(5):358-363. doi:10.4103/0301-4738.185594

21. Daguman IJ, Delfin MS. Correlation of lamina cribrosa and standard automated perimetry findings in glaucoma and non- glaucoma patients. J Ophthalmic Stud. 2019;2(1):1-5. 


\section{Publish your work in this journal}

Clinical Ophthalmology is an international, peer-reviewed journal covering all subspecialties within ophthalmology. Key topics include: Optometry; Visual science; Pharmacology and drug therapy in eye diseases; Basic Sciences; Primary and Secondary eye care; Patient Safety and Quality of Care Improvements. This journal is indexed on PubMed

Submit your manuscript here: https://www.dovepress.com/clinical-ophthalmology-journal
Central and CAS, and is the official journal of The Society of Clinical Ophthalmology (SCO). The manuscript management system is completely online and includes a very quick and fair peer-review system, which is all easy to use. Visit http://www.dovepress.com/ testimonials.php to read real quotes from published authors. 